\title{
Seroprevalence of parvovirus B19 in blood donors: the risks and challenges of blood transfusion in Zambia in the era of HIV/AIDS at the Kitwe Central Hospital, blood bank
}

\author{
Memory Chirambo-Kalolekesha, Trevor Kaile, Florence Mwaba, Victor Daka, Marah Simakando, Sumbukeni Kowa
}

University of Zambia, School of Medicine, Department of Pathology and Microbiology.

\begin{abstract}
Background: Human Parvovirus (B19V) is a small, single-stranded, non-enveloped DNA virus which is pathogenic to humans causing a wide array of clinical complications which include erythema infectiosum, aplastic crisis and hydrops foetalis. It is generally harmless in healthy individuals but may be life threatening in immunocompromised individuals such as patients with sickle cell disease, cancer, HIV and pregnant women. It has been shown to be transmissible by blood transfusion but donor screening for the virus is not yet mandatory in most sub-Saharan African countries including Zambia.

Materials and methods: This was a cross-sectional study undertaken at the Kitwe Central Hospital, blood bank and Tropical Diseases Research Centre at Ndola Central Hospital. A total of 192 blood samples were screened for Ig M antibodies against parvovirus B19 by ELISA.

Objectives: The general objective of the study was to determine the seroprevalence of parvovirus B19 infections among healthy blood donors at the Kitwe Central Hospital blood bank. Specific Objectives were to detect parvovirus B19 Ig M antibodies in donor blood using serology and to analyse the age and sex distribution of parvovirus among blood donors.

Results: The prevalence of parvovirus B19 Ig M in this study was $15.6 \%$. The majority of the positive cases were in the age group 15-22 years (17.8\%) but there was no statistical significance between occurrence of parvovirus and age ( $\mathrm{p}$ value $=0.703$ ). Prevalence in males was higher than in females that is $16.4 \%$ and $13.8 \%$, respectively. The relationship between gender and parvovirus $B 19$ occurrence was however not significant either $(\mathrm{p}$ value $=0.516$ )

Conclusion: This study showed a 15.6\% prevalence rate of acute Parvovirus B19 infections in blood donors at the Kitwe Central Hospital, blood bank. Studies with larger sample sizes are needed to validate these results.

Keywords: Parvovirus B19 in blood donors, blood transfusion, Zambia, HIV/AIDS, Kitwe Central Hospital, blood bank.

DOI: https://dx.doi.org/10.4314/ahs.v18i3.5

Cite as: Chirambo-Kalolekesha M, Kaile T, Mwaba F, Daka V, Simakando M, Kowa S. Sero-prevalence of parvovirus B19 in blood donors: the riskes and challenges of blood transfusion in Zambia in the era of HIVIAIDS at the Kitwe central hospital, blood bank. Afri Health Sci. 2018;18(3): 496-502. bttps://dx.doi.org/10.4314/ahs.v18i3.5
\end{abstract}

\section{Introduction}

Parvovirus B19 is a small, single-stranded, non-enveloped DNA virus which is pathogenic to humans and can result in a wide array of clinical complications ${ }^{1}$. It is generally
Corresponding author:
Memory Chirambo-Kalolekesha, University of Zambia, School of Medicine, Department of Pathology and Microbiology. Email: memorysozichirambo@ymail.com

harmless in healthy individuals but may have a serious clinical outcome in susceptible recipients such as patients with shortened red cell survival such as Sickle cell disease and thalassemia major patients, immunocompromised patients and pregnant women ${ }^{2}$. Parvovirus B19 has been shown to be transmissible by blood transfusion ${ }^{3}$ but donor screening for the virus is not yet mandatory in most sub-Saharan African countries including Zambia. There is need therefore, to establish the occurrence of this virus in the donor population and establish the possible implications on the recipient population which includes the high risk SCD patients and pregnant women.

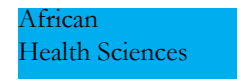

(C) 2018 Chirambo-Kalolekesha et al. Licensee African Health Sciences. This is an Open Access article distributed under the terms of the Creative commons Attribution License (https://creativecommons.org/licenses/BY/4.0), which permits unrestricted use, distribution, and reproduction in any medium, provided the original work is properly cited. 
The pathogenesis of disease in parvovirus B19 infections may be attributed to direct infection or effects on particular cell types, and also effects as a result of the specific acquired immune response $e^{4}$. Patients with haematological disorders are at risk of severe clinical illness due to parvovirus and this is especially common in chronic haemolytic anaemia such as sickle cell disease, thalassemias and hereditary spherocytosis. In these diseases erythroid progenitor cell formation is increased to compensate for red blood cell lysis and B19 infection can suppress erythropoiesis and induce acute erythroblastopenia, which is often referred to as transient aplastic crisis. ${ }^{5}$

Studies have shown that by 15 years of age, about $50 \%$ of the general population are positive for parvovirus B19 Ig $\mathrm{G}$ antibodies ${ }^{6}$, and more than $70 \%$ adults have measurable levels of B19-specific Ig G antibodies ${ }^{7}$. Human parvovirus B19 causes significant morbidity and mortality in children with sickle cell disease ${ }^{8}$. The sickle cell disease trait is in $18 \%$ of the general population in Zambia ${ }^{9}$ but little data has been published about the epidemiology of $\mathrm{B} 19 \mathrm{~V}$ infection and its associated complications in this patient population.

The following were the objectives of the study ;

\section{General objective}

- To determine the seroprevalence of parvovirus B19 infections among healthy blood donors at the Kitwe Central Hospital blood bank.

\section{Specific Objectives}

- To detect parvovirus B19 IgM antibodies in donor blood using serology.

- To analyse the age and sex distribution of parvovirus among blood donors.

\section{Materials and methods}

The study was a cross-sectional type of study involving serological assessment of parvovirus B19 infection in blood donors. The study was conducted at Kitwe Central Hospital blood bank and Tropical Disease Research Cen- tre (TDRC) in Kitwe and Ndola, respectively. Systematic random sampling was used to collect samples. All blood donor samples from healthy voluntary blood donors at $\mathrm{KCH}$ Blood Bank were included in the study. Healthy blood donors were considered as those found asymptomatic at donor interview screening stage and those that tested seronegative for all transfusion transmissible infections screened at the blood bank such as hepatitis and HIV. Blood donor samples found to have other transfusion transmissible infections such as Hepatitis and HIV were excluded from the study.

\section{Sample size}

A total of 192 samples required were calculated using the formula for sample size estimation of a prevalence study and the finite population correction factor.

There is no known prevalence of parvovirus B19 in Zambia therefore an estimated $50 \%$ prevalence was assumed. The formula for sample size estimation for a prevalence study was used as shown below;

$\mathrm{n}=\frac{\mathrm{Z}^{2} \mathrm{P}(1-\mathrm{P})}{\mathrm{d}^{2}}$

Where;

$\mathrm{n}=$ sample size

$\mathrm{Z}=\mathrm{z}$-statistic for a level of confidence

$\mathrm{P}=$ expected prevalence

$\mathrm{d}=$ precision

Therefore $\mathrm{n}=\underline{1.96^{2} \times 0.5(1-0.5)}$

$$
0.005^{2}
$$

$$
\mathrm{n}=384
$$

For the level of confidence of $95 \%$, which is conventional, $\mathrm{Z}$ value is $1.96 . \mathrm{P}$ is the proportion (prevalence to be estimated) by the study. As there is no known prevalence in Zambia an estimated prevalence of $50 \%$ (expressed as a proportion of 1 i.e. 0.5) was used to get the largest possible sample size. Assuming that the prevalence of the disease will lie between $10 \%$ and $90 \%$ a precision of $5 \%$ (expressed as a proportion of 1 i.e 0.005 ) was used. This precision will give the width of $95 \%$ CI as $10 \%$. (Naing et al, 2006). 


\section{Finite population correction factor}

When the sample represents a significant (e.g. $>5 \%$ ) proportion of the population, a finite correction factor can be applied. This reduced the sample size required

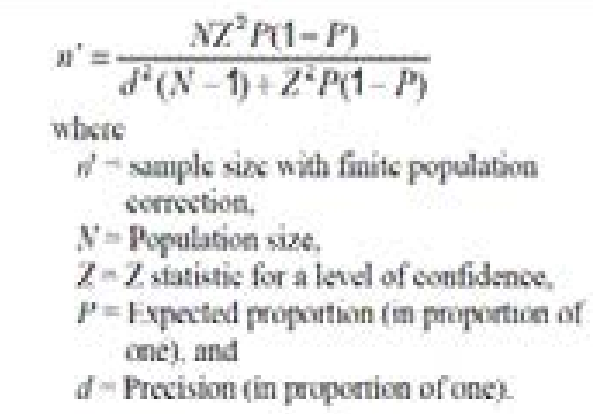

\section{$=192$ samples}

\section{Collection of blood sample}

Whole blood was collected in plain red top containers and spun in a centrifuge to separate serum; the serum was collected using micropipette and transferred into storage vials for future analysis. At least $5 \mathrm{ml}$ of serum was stored in each vial and stored at $-20^{\circ} \mathrm{C}$.

\section{Parvovirus B19 Ig M ELISA test protocol}

Human Parvovirus B19 Ig M levels in blood serum were determined using a competitive human parvovirus B19 IgM immunoassay from mybiosource, USA. Samples were diluted with sample diluents and additionally incubated with Ig G-RF-sorbent, containing hyper immune anti-human Ig G-class antibody to eliminate competitive inhibition from specific Ig $G$ and to remove rheumatoid factors. This pre-treatment avoided false negative or false positive results. Microtiter wells as a solid phase are coated with Parvovirus B19 antigen. Pre-treated samples and ready-for-use controls were pipetted into these wells. During incubation Parvovirus B19-specific antibodies were bound to the immobilized antigens. After a washing step to remove unbound sample and control material horseradish peroxidase conjugated anti-human Ig $\mathrm{M}$ anti- bodies were dispensed into the wells. During a second incubation, the anti-Ig M conjugate bound specifically to Ig $\mathrm{M}$ antibodies resulting in the formation of enzyme-linked immune complexes. After a second washing step to remove unbound conjugate the immune complexes formed (in case of positive results) were detected by incubation with TMB substrate and development of a blue colour. The blue colour turned into yellow by stopping the enzymatic indicator reaction with acidic solution. The intensity of this colour was directly proportional to the amount of Parvovirus B19-specific Ig M antibody in the sample. Absorbance at $450 \mathrm{~nm}$ was read using an ELISA microtiter plate reader.

\section{Ethical considerations}

Ethical clearance was obtained from the University of Zambia Biomedical Research Ethics Committee (UNZABREC) before the commencement of the study. There was no direct contact with the patient as only routine samples were used for the study and hence anonymity of participants was upheld.

\section{Data analysis}

Analysis of the data was performed using IBM SPSS Statistical version 20 for Microsoft and Microsoft Excel 2011. All statistical tests were performed at 5\% significance level or $95 \%$ confidence interval with $\mathrm{p}$-value of $<0.05$ to determine statistical significance. The chi square test was used to ascertain the correlation of age and gender with parvovirus B19 infection. Prevalence ratio was also used to calculate the prevalence percentages of anti-B19 IgM antibodies according to age and sex.

\section{Results}

There was a predominance of male donors observed in this study with a percentage of $69.2 \%$ compared to $30.8 \%$ of the female donors. The mean age of the randomly selected participant donors was 22 years (ranging from 15 to 53 years), of which the highest percentage were of age group $15-22$ years $(67.2 \%)$. 
Table 1: Human Parvovirus B19 Ig M Serology

\begin{tabular}{|l|l|l|}
\hline & \multicolumn{2}{|}{ Frequency } \\
\hline \multirow{4}{*}{ HPV B19 Ig M } & Negative & 162 \\
\cline { 2 - 3 } & Positive & 30 \\
\cline { 2 - 3 } & Total & 192 \\
\hline \hline
\end{tabular}

Table 1: Out of a total 192 blood donors 30 tested positive for HPV B19 Ig M, representing $\mathbf{1 5 . 6 \%}$ prevalence.

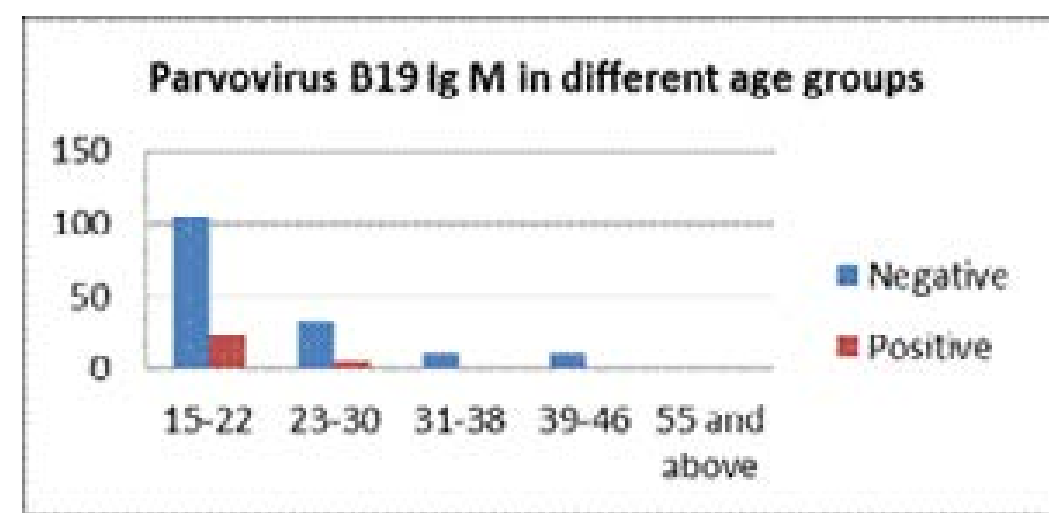

Figure 1: Parvovirus b19 Ig $M$ in different age groups

$17.8 \%$ of the donors aged 15-22years tested positive for HPV B19 Ig M antibodies, followed by $13.5 \%$ of $23-30$ year olds, the 39-46 year olds had the least prevalence. No positive case was detected in the those over 47 years. $P$ value $=0.703$

Table 2: Prevalence of anti-B19 Ig $M$ antibodies according to age and gender

\begin{tabular}{|l|lr|lr|}
\hline Age & \multicolumn{2}{|l|}{ Sex distribution } & $\begin{array}{l}\text { B19-Ig } \\
\text { positive }\end{array}$ & M \\
& & antibodies \\
\hline & male & female & male & female \\
\hline $15-22$ years & 91 & 38 & 18 & 5 \\
\hline $23-30$ & 26 & 11 & 3 & 2 \\
\hline $31-38$ & 10 & 3 & 1 & 0 \\
\hline $39-46$ & 7 & 5 & 0 & 1 \\
\hline$>55$ & 0 & 1 & 0 & 0 \\
\hline Total & 134 & 58 & 22 & 8 \\
\hline & & & & \\
\hline
\end{tabular}

Table 2: As the age increased, the positivity for anti B-19 Ig $M$ decreased in the males and females. Although the prevalence of antibodies (Ig M) were higher in males, the age specific prevalence did not differ significantly $(P$ Value $>0.05)$. 


\section{Discussion}

Human parvovirus B19 is a single stranded DNA virus which is transmitted to susceptible individuals via respiratory secretions and contaminated blood or blood products. Post-transfusion transmission of human parvovirus B19 is an established problem globally. ${ }^{10}$ Immunocompromised individuals might fail to eradicate the virus resulting in a state of chronic anaemia. ${ }^{11}$ There is no published data on the prevalence of parvovirus B19 in Zambia. The current study aimed at addressing this gap by using ELISA for screening blood donors to determine seroprevalence rate of parvovirus B19 acute infections using antihuman globulin titres ( $\operatorname{Ig} \mathrm{M}$ ) in healthy blood donors. We also postulated in the risks and challenges for blood transfusion in the era of HIV/AIDS at Kitwe Central Hospital in Zambia.

The majority of the donors in this study were males representing $70 \%$ of the total donors screened. This picture is similar to most blood banks around most of Africa. In a similar study conducted by Kumar et al in India in 2013, 98\% were male and only $2 \%$ were females. ${ }^{12}$ Another study done in Nigeria in 2013 by Musa et al had 94.3\% male donors against $3.4 \%$ females. ${ }^{10}$ This variation in between male and female donor may be attributed to the fact that women are excluded due to pregnancy and lactation. However, the main cause for asking women to defer from giving blood is believed to be because they generally have low haematocrit or low iron levels. This study showed no significant statistical correlation between gender and parvovirus B19 infection ( $\mathrm{P}$ value $=0.516$ )

More than $50 \%$ of the donors in this study were aged between 15-22 years. The mean age of the donors was 22 years and the oldest donor was 53 years old. A study conducted in Nigeria to establish blood donor practices showed a similar age group pattern. In this study ages of prospective donors ranged from 15 years to 56 years with a mean age of 27.89 years and over $65 \%$ of the donors were aged between 21 to 30 years. There was no significant statistical correlation between age and Parvovirus $\mathrm{B} 19$ infection in this study $(\mathrm{P}$ value=0.703). Some studies have noted an increase in seroprevalence of the virus with age ${ }^{13}$. A study by Emiasegen et al in $2011^{14}$ reported increase in seroprevalence with age as well as the reviews of Heegard and Brown in $2002^{15}$ and Kaur and Basu in
$2005^{16}$. In this study however, there was a decrease in seroprevalence with increase inage. The difference in sampling populations may be a factor of this difference. The study by Emiasegen et al for example used pregnant women as opposed to the blood donors used in this study. The findings of this study however, agree with that of Emiasegen et $\mathrm{al}^{14}$, and most other studies in the sense that age had no statistically significant effect on Human Parvovirus infection.

Our study revealed a high prevalence of $15.6 \%$ for acute infections of Parvovirus B19 in our blood donor community. The prevalence of $\mathrm{Ig}$ M to B19 in blood donors or in other healthy populations is usually below $2 \%$, but it can be higher depending on the time of study in relation to the epidemic cycle. ${ }^{12}$ Doyle and his co-worker found seroprevalence of $1 \%$ prevalence among American blood donors ${ }^{17}$ while Munoz reported $0 \%$ in Spanish blood donors ${ }^{18}$. In addition to geographical and seasonal variations, differences in sampling methods, population size and assay methods are likely causes of the differences in seroprevalence rates observed. A study done in Nigeria using parvovirus Ig M ELISA showed a prevalence rate of $14.8 \%{ }^{10}$ which is comparable to the one observed in this study.

The risks of having a higher prevalence of Parvovirus B19 infections in donated blood is a threat to the health of the blood recipients, who are in many circumstances immunocompromised such as children, sickle cell disease patients, cancer patients, pregnant women and those with acquired immunodeficiency's like HIV. Transfusing blood contaminated with Parvovirus B19 compromises the health of immunodeficient patients who may later become chronically infected ${ }^{19}$. During pregnancy, the virus can be transmitted in utero which can sometimes lead to abortions or hydrops fetalis ${ }^{20}$. It can also cause serious complications such as aplastic crises, pneumonia and multi organ damage ${ }^{21}$. The prevalence of HIV in Zambia is relatively high $(14.3 \%$ among adults $)$, around 1.2 million people in Zambia are living with $\mathrm{HIV}^{22}$. Because of the increase in the HIV rates in Zambia, there are so many opportunistic infections that make one susceptible to many diseases and cancers that eventually lead to one needing blood because of haematological disorders. Pa- 
tients with haematological disorders are at risk of severe clinical illness ${ }^{23}$. Parvovirus B19 in sickle cell may persist and lead to chronic anaemia. The sickle cell trait is present in approximately $18 \%$ of the general population in Zambia ${ }^{9}$. Cancer patients are also at risk of contracting the Parvo B19 virus especially because they need multiple courses of chemotherapy, and this has to be done when the haemoglobin levels are normal and so blood is usually transfused in them frequently. In immune-compromised patients, Parvovirus B19 is associated with glomerulonephritis, myocarditis and hepatic failure which complicates their treatment and condition ${ }^{24}$.

In healthy hosts, B19 infection is generally harmless and causes self-limiting sub-clinical erythroid aplasia, followed by rash or arthralgia. Nevertheless, in patients with diminished production or increased loss of erythrocytes, B19 infection results in a severe drop in haemoglobin levels and in anaemia, this could be life-threatening. It has been recognized as a cause of cytopaenia in immunocompromised patients, including organ transplant recipients, patients with congenital and acquired immunodeficiency, and cancer patients ${ }^{25}$.

The mandatory screening of donated blood for parvo B19 virus infections should be introduced in Zambia especially that there is an increase in the number of HIV/ AIDS, cancers, haematological conditions and pregnancies. Close monitoring of high risk groups for viral infection is important for disease prevention.

\section{Conclusion}

This study showed a $15.6 \%$ prevalence rate of acute parvovirus B19 infections in healthy blood donors at the Kitwe Central Hospital, blood bank. The risks and challenges of a high prevalence to this problem is that human B19V is contagious. If left unhandled, the infections can even be transmitted in the household, at day cares and in schools without being observed. It poses an adverse transfusion risk especially in high risk group of patients that need blood transfusion. This is so because parvovirus B19 affects the erythroid progenitor cells, which are found in human bone marrow, fetal liver, human umbilical cord and peripheral blood. The high risk group includes pregnant women, $\mathrm{Rh}$ isoimmunised preg- nancies requiring intrauterine transfusion, patients with congenital or acquired haemolytic anaemia and patients with cellular immunodeficiency who have no detectable antibodies to B19.

\section{Recommendations}

Statistical tests however show that there is no association with sex or gender and parvovirus B19 infection. A lack of data on the burden of parvovirus B19 on our population is a major concern. The findings from this study suggest the need to conduct a national level seroprevalence of human parvovirus B19 among blood donors as a matter of public health concern. Secondly, the Zambia National Blood Transfusion Service (ZNBTS) should consider routine screening of blood donors for B19 to avoid contaminated transfusion, particularly for immune compromised patients. The risks of transfusing contaminated blood with B19 increases on the risks of the blood recipients to have many conditions that will threaten their health. Patients other than those in the high-risk groups would continue to receive blood products that have been produced in accordance with current safety criteria.

\section{References}

1. Brown CS, van Bussel MJA, Wassenaar ALM, et al.(1990) An immunofluorescence assay for the detection of parvovirus B19 Ig G and Ig M antibodies based on recombinant viral antigen. Journal of Virological Methods. 29:53

2. Marano G, Vaglio S, Pupella S, Facco G, Calizzani G, Candura F, Grazzini G. Human Parvovirus B19 and blood product safety: a tale of twenty years of improvements. Blood Transfusion. (2015) 13(2), 184

3. Koppelman MH, Rood IG, Fryer JF et al. Parvovirus B19 genotype 1 and 2 detection with real time polymerase chain reaction assays. Vox Sang. 2007;93:208-15.

4. Kerr S, O'Keeffe G, Kilty C, Doyle S. Undenatured parvovirus B19 antigens are essential for the accurate detection of parvovirus B19 IgG. Journal of Medical Virology. (1999); 57:179e185.

5. Xu J, Raff T, Muallem N, Neubert AG. Hydrops fetalis secondary to parvovirus B19 infections. The Journal of the American Board of Family Practice. (2003); 16: 63-68.

6. Corcoran A, Doyle S. Advances in the biology, diag- 
nosis and host-pathogen interactions of Parvovirus B19. Journal of Medical Microbiology. (2004); 53: 459-475.

7. Kerr S, O'Keeffe G, Kilty C, Doyle S. Undenatured parvovirus B19 antigens are essential for the accurate detection of parvovirus B19 IgG. Journal of Medical Virology. (1999); 57:179e185.

8. Smith-Whitley K, Zhao H, Hodinka RL. Epidemiology of human parvovirus B19 in children with sickle cell disease. Blood Journal. (2004); 103:422-7.

9. Nchimba Lweendo. Prevalence of Hepatitis B and C in Sickle Cell Disease patients at University Teaching Hospital, Lusaka, Zambia. (2015).

10. Musa Sunday AU, Banwat Edmund B, Zhakom Ponfa, Rumji Elisha M, Yakubu Rebecca K, Rufai Olalekan A. Iosr Journal Of Pharmacy (e)-ISSN (2013); 2250-3013, (p)-ISSN: 2319-4219 Www.Iosrphr.Org Volume 3, Issue 3 Pp 66-70

11. Koch WC, G Massey, CE Russel, SP Adler. Manifestations and treatments of parvovirus B19 infection in immunocompromised patients. Journal of Peadiatrics. (1990); 116:355-359

12. Lt Col Satish Kumar, Col R.M. Gupta, Col Sourav Sen, Brig RS Sarkar, Col J Philip, Col Atul Kotwal, SM f, SH Sumathi. Seroprevalence of human parvovirus B19 in healthy blood donors, Medical Journal of armed forces, India. (2013); 268-272

13. Crane J. Parvovirus B19 infection in pregnancy. Journal of Obstetrics and Gynaecology Canada. (2002); 24(9):727-43.

14. Emiasegen SE, Nimzing L, Adoga MP, Ohagenyi AY, Lekan R. Parvovirus B19 antibodies and correlates of infection in pregnant women attending an antenatal clinic in central Nigeria. Memorial Institute of Oswaldo Cruz: (2011); 106:227-31.
15. Heegaard ED, Brown KE. Human parvovirus B19. Clinical Microbiology Review. (2002); 15:485e505.

16. Kaur P, Basu S. Transfusion-transmitted infections: Existing and emerging pathogens; Journal of Postgraduate Medicine. (2005); 51(2): 146-151.

17. Doyle S, Kerr S. Seroprevalence of parvovirus B19 among blood donors in USA. Journal of Virological Methods. (2000); 90(2):143-52.

18. Munoz S, Alonso M. Seroprevalence versus parvovirusB19 in blood donors. (1998); 16 (4)161-2.

19. Servant A, Laperche S, Lallemand F, Marinho V, De Saint Maur G, Meritet JF, et al. Genetic diversity within humanerythroviruses: identification of three genotypes. Journal of Virology. (2002); 76:912e34

20. Puccetti C, Coritoli M, Baninina F, Ceri F, simonanaza $G$ et al. Parvovirus B19 in pregnancy : Possible consequences of vertical transmission. Prenatal Diagnosis Journal. (2012); 32:897-902.doi:10.1002/ pd 3930

21. Eid AJ, Chen SF, AST. Infectious Diseases Community of Practice: Human Parvovirus B19 in solid Organ transplantation. American Journal of Transplants. (2013); 13 Supplement 4:201-205

22. http// www.unicef.org/zambia/5109_8459.html

23. Regaya F, Oussaief L, Bejaoui M, Karoui M, Zili M, Khelifa R. Parvovirus B19 infection in Tunisian patients with sickle-cell anemia and acute erythroblastopenia. (2007); Biomed central Infectious Diseases Journal ;7:123.

24. Torok TJ. Unusual clinical manifestations reported in patients with parvovirus B19 infection. MonogramVirology. (1997); 20:61-92

25. Florea AV, Ionescu DN, Melhem MF. Parvovirus B19 infection in the immunocompromised host. Archives of Pathology and Laboratory Medicine. (2007);131:799-804. 